\title{
Global Entrepreneurship and Institutions: An Introduction
}

\author{
Jonathan Levie \\ Hunter Centre for Entrepreneurship, University of Strathclyde \\ Glasgow, United Kingdom \\ j.levie@strath.ac.uk \\ Erkko Autio \\ Imperial College London Business School \\ London, United Kingdom \\ erkko.autio@imperial.ac.uk \\ Zoltan Acs \\ School of Public Policy, George Mason University, \\ Fairfax, VA, USA \\ zacs@gmu.edu \\ Mark Hart \\ Aston University \\ Birmingham, United Kingdom \\ mark.hart@aston.ac.uk
}

\begin{abstract}
This paper is an introduction to the special issue from the 4th Global Entrepreneurship

Monitor Research Conference held at Imperial College Business School, London, in 2010.

The paper has two objectives. The first is to summarize the history of the GEM consortium, some of the contributions that it has delivered, and some challenges and opportunities ahead. The second is to present a summary of the papers in the context of the utility of GEM data in comparative entrepreneurship research.
\end{abstract}

Keywords: Entrepreneurship, Economic Development, Institutions, Public Policy JEL Classifications L26, O1, O2

This version: August 2013. The final publication in Small Business Economics is available at Springer via http://link.springer.com/article/10.1007\% 2Fs11187-013-9516-6 


\section{Introduction}

This special issue features papers originally presented at the 4th Global Entrepreneurship Monitor Research Conference held at Imperial College Business School, London, in 2010. Consistent with the founding objectives of the GEM consortium, the conference examined the following questions: How does entrepreneurship contribute to economic development? What should governments do to make their economies more entrepreneurial? Why are some countries more entrepreneurial than others? And, what drives entrepreneurship in different contexts?

Before introducing the special issue papers, we take a retrospective look at the history of the GEM consortium and some of the contributions that it has delivered. At the time of writing, GEM is in its fifteenth cycle of data collection. Following a pretest with five countries in 1998, the first cycle was in 1999 with a consortium of teams from 10 countries. With 95 different economies surveyed by 2012, GEM is still adding new countries to its annual data collection effort. Given the difficulty of holding consortia of voluntary participants together - especially in academia - this is a remarkable achievement. Before introducing the papers and highlighting their contributions, let us therefore reflect on how GEM got started and what it has contributed. After introducing the papers, we offer our thoughts on the future challenges and opportunities for GEM and where it might be heading.

\section{A Brief History of GEM}

The Global Entrepreneurship Monitor $\left(\mathrm{GEM}^{1}\right)$ dataset was initiated in 1997, when Paul Reynolds moved to London Business School to start work on an idea that Michael Hay and Bill Bygrave had for a World Enterprise Index that would track entrepreneurship in

\footnotetext{
${ }^{1}$ The original acronym was GOEI, or Global Opportunity and Entrepreneurship Index. The name Global Entrepreneurship Monitor, abbreviated as GEM, was proposed by Erkko Autio, who had just bought the gems for the engagement ring for his future wife.
} 
countries, similar to how the World Competitiveness Yearbook monitors national competitiveness. Other original members of the research team were Erkko Autio and Jonathan Levie, both of whom were visiting researchers at LBS at the time, and Harry Sapienza, who was on sabbatical at LBS.

Before starting work on GEM, Paul Reynolds had launched and continued to coordinate another major initiative to track entrepreneurial processes: the Panel Study of Entrepreneurial Dynamics or PSED (Reynolds, 2007). As an extension of the Wisconsin Entrepreneurial Climate study carried out in 1990s (Reynolds and White, 1997), the PSED was mostly US-based panel study that monitored the entrepreneurial engagement processes in a cohort of nascent entrepreneurs. The core screening questions of GEM's Total Early-Stage Entrepreneurial Activity index (TEA) were adopted from PSED. As PSED already had international participation (notably, from Norway, Sweden, Canada, and The Netherlands, where PSED protocols were used for country panels), Reynolds was ideally equipped to launch the GEM study.

Both the PSED and GEM data collection can be used to track individual activity in venture creation and management and also to track ventures as units of analysis (using the respondent as the informant for the venture). The important difference between PSED and GEM is that PSED is an individual-level panel study: it tracks individuals over time. GEM, on the other hand, is a country-level cross-sectional panel study that takes regular snapshots made up of cross-sections of individuals within countries over time. Whereas PSED was designed to study who completes the process of new firm formation once started, the GEM study sought to explore what makes countries entrepreneurial. Because of its wide crosscountry coverage, GEM has subsequently become an important data resource for comparative entrepreneurship research, as highlighted by the selection of papers in this special issue. 


\section{The utility of GEM data in comparative entrepreneurship research}

This special issue features articles that use Global Entrepreneurship Monitor data to explore relationships between entrepreneurship and its contexts, on the one hand, and entrepreneurship and aspects of economic development, on the other. The GEM dataset has several features that make it particularly well suited for the study of such questions.

First, GEM is the only globally harmonized dataset dedicated to the study of individual-level entrepreneurial behaviors across countries. This harmonization is achieved at two levels: screening and processing. First, the GEM dataset uses the same screening protocol in all countries to identify 'nascent', 'new' and 'established' entrepreneurs. This minimizes difficult-to-control bias resulting from, e.g., cross-country variation in new venture registration protocols or different operational definitions of new ventures. Furthermore, representative samples of the adult working age population (18-64 years old) are surveyed in each country; typically, randomized cluster sampling and telephone or person-to-person interviews are used to ensure representativeness. This means that GEM data is free from certain types of self-selection. For example, in the case of registration, GEM captures both registered and unregistered new firm entries, permitting estimation of prevalence rates of both formal and informal entrepreneurial entries.

GEM also uses harmonized methodologies to process the data: all national datasets are processed and harmonized centrally, further reducing difficult-to-control variation resulting from country-specific differences in data processing protocols (Reynolds et al., 2005). This harmonization enhances GEM's suitability for comparative entrepreneurship research.

Second, GEM data is clustered, both across countries and within countries across time. Clustering across countries is important, since this feature enables the study of the important policy question: What makes countries entrepreneurial? As national policy-makers 
seek to harness the potential of entrepreneurship for economic dynamism, they need factual evidence on country-level attributes that facilitate and inhibit societally and economically beneficial forms of entrepreneurial action. For the production of such insight, harmonized cross-country data is needed. The clustering across countries of the GEM data permits the analysis of country-level associations. This clustering also makes it possible to explore crosslevel effects of country-level attributes on individual-level entrepreneurial attitudes, activities and aspirations using multi-level analytical techniques.

Third, the GEM data offers country-level cross-sectional time series of up to 15 years for some countries. In this time scale, institutional conditions can vary considerably. This clustering across time means that GEM enables not only the study of the effect of crosscountry variation on entrepreneurial processes, but also, the study of within-country change in institutional conditions on the same outcomes. This clustering across time makes it possible to track not only cross-sectional associations between institutional conditions and entrepreneurial outcome variables, but also, to claim causal associations between the same sets of variables.

Finally, GEM uses several screening questions to ensure that it tracks genuine entrepreneurial activity and not, e.g., registrations of non-active entities or new incorporations resulting from corporate restructurings. Several screening questions also make it possible to isolate specific sub-groups of entrepreneurial entries - e.g., to screen out selfemployment by excluding new businesses that do not expect to employ anyone beyond the focal entrepreneur; to pick only high-aspiration entrepreneurial entries by selecting only those ventures that aspire for rapid employment growth; or, for example, to focus on corporate entrepreneurship by selecting only those individuals involved in new start-ups on behalf of their employers. 
These attractive features of the GEM data have inspired a growing body of research in comparative entrepreneurship that explores associations between country-level attributes and various aspects of the entrepreneurial processes and seeks to link these to meaningful outcome variables (Autio and Acs, 2010; Bowen and De Clercq, 2008; Estrin et al., 2012; Levie and Autio, 2011; van Stel et al., 2007). Drawing mostly on the institutional economics tradition (Djankov et al., 2002; Djankov at al., 2003; Peng, 2002), this work assumes that entrepreneurial processes are both regulated by, and in return influence, regional and countrylevel attributes such as formal and informal institutions and economic and demographic conditions. This interaction, then, is assumed to influence salient outcome variables, although evidence thus far remains relatively thin.

To assess the value of the GEM data for comparative entrepreneurship research, it is informative to review the 'state-of-the-art' of comparative entrepreneurship research before the GEM project was launched in 1997, and also, the major insights GEM-based research has contributed to this domain. Back in 1997, entrepreneurship research was dominated by output from Western economic contexts, mostly from North America and Western and Northern Europe. There was very little variation in the contexts where entrepreneurial processes were studied and almost no systematic comparative research across countries. Comparative crosscountry studies existed, but these were based on ad-hoc collaborations between two or more research groups, typically combining survey data. There was no systematic tracking of entrepreneurial entries across countries, although the European Commission had started efforts to track entrepreneurship with its SME Observatory. This dataset was unable to accurately track entrepreneurial entries, however.

When the GEM project was started, some of its initial assumptions (both implicit and explicit) reflected this dearth of evidence-based insight into the quality and effects of entrepreneurship across countries. It was assumed that more entrepreneurship is always 
better, and there was little or no appreciation that the substantive content of entrepreneurial processes would be more or less the same everywhere ${ }^{2}$. Against this background, one can appreciate the range of insight contributed by GEM data:

The first GEM report published in 1999 revealed important, almost order-ofmagnitude differences in the prevalence rates of entrepreneurial entries (Reynolds et al., 1999). Notably, it was found that prevalence rates in the US were more than 10 times as high than those in Japan.

As more countries joined the consortium, it was soon found that the highest rates of entrepreneurial entries were not to be found in the richest countries as originally assumed, but rather, in low-income economies such as Brazil (the first low-income country to join the consortium), and subsequently, countries such as Uganda, Peru, and Zambia. This discovery triggered the introduction of the now well established (even if somewhat simplifying) distinction between 'opportunity-driven' and 'necessity-driven' entrepreneurial entries, with necessity-driven entrepreneurial entries dominating in low-income contexts (Reynolds et al., 2001).

Further insight into the existence of important qualitative differences among entrepreneurial entries was produced with the introduction of the first GEM report on 'highaspiration' entrepreneurship (Autio, 2005), which found (consistent with Birch, 1997) that the bulk of anticipated job creation through entrepreneurial entries was attributable to a relatively small group of high-aspiration entrepreneurial entries. This finding has subsequently prompted (together with similar findings from other studies) a major shift in entrepreneurship policy emphasis away from 'small business' towards initiatives targeted at high-potential entrepreneurs.

\footnotetext{
${ }^{2}$ Although Baumol had published his seminal hypothesis regarding 'productive', 'unproductive' and 'destructive' entrepreneurship in 1990, this thesis had not been tested due to lack of suitable data (Baumol, 1990; Weitzel et al., 2010; Desai et al., 2013).
} 
An important demographic insight concerns the role of women entrepreneurs. GEM reveals the share of women entrepreneurs of all entrepreneurs to vary considerably across countries but be mostly within the range of 2:1 to up to 1:1 male-female ratios (Minniti et al., 2005).

The GEM dataset also captures interesting natural experiments. One such came about in the early 2000s when Argentina suffered a severe economic crisis, and its prevalence rates of entrepreneurial entries rose considerably (Bosma and Levie, 2009), suggesting that entrepreneurship may operate as a buffer against sudden turns in job markets. Similar upshots have been subsequently witnessed in in some (but not all) Western economies after 2008.

Over the years, GEM has incorporated special themes into its annual data collection cycle that explore current issues in entrepreneurship. For example, the 2008 cycle collected additional data on training in starting a business. This enabled GEM researchers to overcome many issues that make causative attributions to training difficult, including self-selection, delays in outcomes, national context, and individual level demographic differences in entrepreneurial propensity (Coduras et al., 2010).

An intriguing, as yet emerging finding was revealed when a measure of corporate entrepreneurship (i.e., entrepreneurial efforts undertaken on behalf of the employer) was added to the repertoire of GEM measures (Bosma et al., 2012). This measure extends empirical operationalizations of entrepreneurship beyond new venture contexts to capture entrepreneurial effort in the spirit of Baumol (1990). When the country-level measures of nascent, new and corporate entrepreneurship are combined, differences across countries are considerably reduced, consistent with Baumol's notion that the level of entrepreneurial effort should not vary dramatically across countries; only its forms should, as regulated by incentives set by country-specific institutions. 
A recent estimate of informal entrepreneurship (i.e., entrepreneurial entries that do not register with authorities) formed by combining survey-based GEM data with World Bank Enterprise Snapshot survey suggests dramatic cross-country differences in the levels of formal and informal entrepreneurial entries, respectively (Autio and Fu, 2013). According to this estimate, ratios between formal and informal entries may vary by a factor of over 1,000 across the most and the least developed countries, again emphasizing that in developing economies, entrepreneurship is expressed in different ways than in high-income economies.

The above examples illustrate the value of the GEM dataset in providing harmonized descriptive data on entrepreneurial processes at the country level. The descriptive findings highlighted above should offer plenty of opportunity for follow-on comparative entrepreneurship research that explores underlying causes for the patterns observed. Emerging findings from such efforts appear to confirm that this is a rich field of study in its own right - and that country-level institutional and economic conditions appear to exercise important influence on forms and patterns of entrepreneurial processes within a given country.

\section{Articles in this Special Issue}

The articles included in this special issue provide examples of GEM-based research that moves beyond description to insight. The special issue includes a review of the literature generated by GEM scholars and four cross-national studies that illustrate the value of combining GEM data with other cross-national databases to illuminate policy issues in Global Entrepreneurship, Innovation and Economic Development. The issues considered are informal investment, entrepreneurial re-entry following failure, culture and subjective wellbeing, or "happiness". 
The cross-national, multi-level approach of these studies, and the extensive use of other cross-national data, represents an advance on the studies in previous special issues on GEM-based research. A particular advance is the gradual adoption of multi-level techniques that take advantage of the across-country and across-time clustered properties of the GEM data. An application of this method is highlighted in the paper by Simmons, Wiklund and Levie. Although GEM-based research applying this approach remains scant, as noted by the review article by Alvarez, Amorós and Urbano, the take-up of this approach is rapidly increasing. We next introduce the articles highlighted in this special issue.

The literature review by Claudia Alvarez, José E. Amorós and David Urbano reviews GEM-based articles published between 2000 and January 2012 and highlights theoretical and methodological trends in the use of GEM data. Summarizing research published in 95 articles, they find that the majority of GEM-based articles explored effects of formal and informal institutions on entrepreneurship, with a significant number of articles also exploring economic conditions. Although the studies reviewed had used individual- and country-level data almost equally, only two articles in their review had applied multi-level theorizing and analytical techniques to explore more complex relationships by January 2012. They also observed an increasing trend in terms of the quality of publication outlets. Although no GEM-based studies had been published in 'A-star' journals in management or economics by the end of January 2012, an increasing number of articles had been published in 'A' journals such as the Journal of International Business Studies, Journal of Management Studies and Strategic Entrepreneurship Journal. They conclude by recommending increased application of multi-level analysis techniques in the analysis of GEM data, and also, note the utility of combining GEM data with data from other sources to increase the range of research questions that can be explored using this asset. 
The second paper article by Andrew Burke, André van Stel, Chantal Hartog, and Abdel Ichou makes use of the annual collection of data by GEM on investment by individuals in other people's start-ups, or informal investment. This enables them to test the hypothesis that demand for informal investment tends to create its own supply - a hypothesis that has significant policy implications. Burke et al. measure micro and macro effects on individual propensity to be an informal investor and on the amount that investors invest. They draw on cross-national data on venture capital and economic statistics from the World Bank and the OECD to measure macro effects. They find that informal investment volume is, at least in part, driven by entrepreneurial activity - a finding that suggests that the supply of funding for new ventures is partly self-correcting. This finding is in contrast with numerous calls to increase funding for new ventures in order to increase entrepreneurship and suggests that governments need to take a broader look at systemic bottlenecks when seeking to harness the potential of entrepreneurship for economic dynamism.

The third paper by Sharon Simmons, Johan Wiklund and Jonathan Levie examines the effect of national differences in the stigma of failure on re-entry patterns of failed entrepreneurs by combining the GEM data with the World Bank Development Indicators (WDI) and the European Commission Flash Barometer. GEM collects data on the reasons for exit, enabling the authors to separate out failed from other exited entrepreneurs and address a question of intense policy interest: what are the welfare effects of stigmatizing failed entrepreneurs? One argument states that stigmatization is good to the extent it prevents 'serial failures'. Another argument emphasizes the importance of learning from failure for entrepreneurial success, thereby advocating no stigmatization. Simmons and colleagues' multi-level analysis reveals an interesting interaction between informal institutions (i.e., attitudes of the public towards failed entrepreneurs) and information disclosure (i.e., public 
availability of information on business failure), thereby demonstrating that the question of stigmatization and re-entry of failed entrepreneurs is more nuanced than often assumed.

In the fourth paper, Dirk DeClercq, Dominic Lim and Chang Hoon Oh combine national level culture measures derived from the Schwartz Values Survey and data from two GEM surveys: the Adult Population Survey and the National Expert Survey to test the moderating effect of national culture on the influence of national institutions (such as informal finance and education for entrepreneurship) on early-stage entrepreneurial activity at the country level. They find that country-level cultural values of hierarchy (vs egalitarianism) and conservatism (versus individualism) moderate negatively the effect of informal investment capital availability on early-stage entrepreneurial entry: in more hierarchical and conservative cultures, the effect of informal investment capital availability on early-stage entrepreneurial entry was found to be weaker. This finding thus reveals an interesting interaction between informal institutions and resource munificence that is consequential for entrepreneurial entry.

In the final paper, Wim Naudé, José E. Amorós and Oscar Cristi explore the possible relationship between a nation's happiness and entrepreneurship. They start from the increasingly popular position that material welfare, as measured by GDP, is only one dimension of a country's development, and that subjective well-being, or "happiness" is therefore a legitimate topic for research. Drawing on happiness data from the World Database on Happiness and the Gallup World Poll, and GEM data from the Adult Population Surveys, they find some evidence for a curvilinear relationship between opportunity-driven early-stage entrepreneurial activity and happiness at the national level, and also for a positive effect of happiness levels on opportunity-driven early-stage entrepreneurial activity. 


\section{Conclusion and Future Directions}

The articles featured in this special issue provide a representative sample of GEMbased research. Some GEM studies, including the papers by DeClercq et al. and Naudé et al., focus on country-level phenomena using country-level aggregates of GEM data and combine these with variables from secondary sources. Other studies explore phenomena at different levels of analysis essentially separately, as done by Burke et al. Still further studies employ multi-level designs, as exemplified by Simmons et al. The variety of these approaches illustrates the range of research questions that the GEM data can be used to explore.

As the GEM data collection effort is approaching adulthood, it is worth asking where GEM might be heading. As noted earlier, little was known about entrepreneurship as a country-level phenomenon at the time when GEM was started. The absence of harmonized cross-country datasets meant that little cross-country comparative entrepreneurship research existed, and the need for a collaborative effort such as GEM was clear. However, interest in the links between entrepreneurship and economic development has considerably increased since those days, and a number of datasets have become available for researchers - the most important of these being the World Bank's Doing Business dataset, which monitors institutional conditions for new venture creation and operation, and the World Bank Enterprise Snapshot, which monitors new business incorporations across countries. In addition, in regions such as the EU, there is increasing harmonization across national statistics offices in terms of procedures used to identify and track new incorporations. One might therefore ask whether GEM is still needed.

Our answer to the above question is affirmative: it is necessary to continue collecting GEM data because GEM offers distinctive features that make it particularly amenable for comparative entrepreneurship research. It is the only wide-coverage dataset that tracks individual-level entrepreneurial attitudes, activities and aspirations and features across- 
country and across-time clustering. Because GEM is survey-based, it can flexibly pick up and add new questions to address phenomena of current interest. A recent example is the inclusion of questions to track formal and informal entrepreneurial entries to respond to recent interest in the topic (Godfrey, 2011). Over the years, GEM has refined its data collection and harmonization methods to the extent that it compares favorably with all other wide-coverage, individual-level datasets. A particular strength of GEM is that, unlike many global surveys, it is grounded in national academic teams who understand their country context, the nuances of language, and the best means of data collection for their country. This is why we believe that GEM can only continue to grow in value, the longer the GEM teams persist in collecting the data. A salient recognition of this value came in 2011 when the European Commission DG Employment, Social Affairs \& Inclusion started to sponsor the collection of additional GEM data in EU countries for inclusion in a series of OECD reports on Entrepreneurship and Social Inclusion.

This general positive outlook does not mean, however, that GEM will not face important challenges. As noted by Alvarez et al., GEM's publication track record does not appear to fully match the intrinsic value that we see in the dataset. Relatively few GEM-based research papers have been published in A-journals. As Alvarez et al. note, this is partly a reflection of the heterogeneity of GEM country teams, with only a few teams having experience in A-journal publication. While one may hope this gap to correct itself over time, it is important to continue to promote GEM data to researchers outside GEM teams. For the moment, there are still too few non-GEM scholars taking advantage of this dataset, partly perhaps because too few of them realize that it is freely available, and partly because the dataset is very complex, and learning to use it requires some effort. Tellingly, most of the empirical papers in the special issue were written by mixed groups of GEM and non-GEM team members; this approach could serve as a bridge to a wider user base. 
Another important challenge concerns GEM's ability to maintain flexibility and relevance. Although the GEM survey can accommodate new questions, this does not mean that it will automatically do so. For GEM to continue to prosper, it needs a governance structure that provides strong intellectual leadership, thereby keeping it relevant and on top of current issues.

A third important challenge concerns GEM's continued relevance for policy. When the GEM data was first reported, its impact on policy-makers was considerable, as it provided the first global view of entrepreneurship across countries. To continue to attract sponsorship from national policy-makers (each GEM country team has to find sponsors for data collection in their country), GEM needs to constantly offer fresh and relevant policy insight. Doing so requires continued investment in the collection of new data and new questions; in analytical methods; and in finding new ways to use the data to address policy-relevant questions. One encouraging development is the Global Entrepreneurship and Development Index GEDI, which combines GEM data with secondary data to profile 'National Systems of Entrepreneurship' (Acs et al., 2013a,b).

In summary, we see GEM as a hugely valuable dataset that, after 15 annual cycles, still offers considerable untapped potential for use in comparative entrepreneurship research. This dataset has been barely discovered by development economists, for example. We see a particular role for GEM data in researching the intersection of entrepreneurship and economic development, particularly when applying appropriate multi-level analysis techniques supported by coherent multi-level theorizing. As the project descriptions, documentation of the data collection, and the preparation of harmonized, cross year data sets improve, more researchers outside the GEM teams should realize the potential of this unique resource for scholarly and policy analysis. 


\section{References}

Acs, Z. J., Autio, E., \& Szerb, L. (2013). National systems of entrepreneurship: Measurement issues and policy implications. Research Policy, doi:10.2139/ssrn.2008160

Acs, Z. J., Szerb, L., \& Autio, E. (2013). Global entrepreneurship \& development index 2012. Cheltenham: Edward Elgar.

Autio, E., \& Acs, Z.J. (2010). Intellectual property protection and the formation of entrepreneurial growth aspirations. Strategic Entrepreneurship Journal, 4(3), 234-251.

Autio, E., \& Fu, K. (2013). Economic and political institutions and entry into formal and informal entrepreneurship. Asia Pacific Journal of Management (in print).

Baumol, W.J. (1990). Entrepreneurship: productive, unproductive and destructive. Journal of Political Economy 98(5), 893-921.

Bosma, N. \& Levie, J. (2010). Global entrepreneurship monitor 2009 global report. London: Global Entrepreneurship Research Association.

Bosma, N., Wennekers, S., \& Amoros, J.E. (2012). Global entrepreneurship monitor2011 extended report: Entrepreneurs and entrepreneurial employees across the globe. London: Global Entrepreneurship Research Association.

Bowen, H. P., \& De Clercq, D. (2008). Institutional context and the allocation of entrepreneurial effort. Journal of International Business Studies, 39(1), 1-21.

Coduras, A., Levie, J., Kelley, D., Saemundsson, R. \& Schott, T. (2010) Global entrepreneurship monitor 2009 entrepreneurship education and training special report. London: Global Entrepreneurship Research Association.

Desai, S., Acs, Z.J., \& Weitzel, U. (2013). A model of destructive entrepreneurship: Insight for conflict and postconflict recovery. Journal of Conflict Resolution, 57(1), 20-40.

Djankov, S., Glaeser, E., La Porta, R., Lopez-de-Silanes, F., \& Shleifer, A. (2003). The new comparative economics. Journal of Comparative Economics, 31(4), 595-619. 
Djankov, S., La Porta, R., Lopez-de-Silanes, F., \& Shleifer, A. (2002). The regulation of entry. Quarterly Journal of Economics, 117(1), 453-517.

Estrin, S., Korosteleva, J., \& Mickiewicz, T. (2012). Which institutions encourage entrepreneurial growth aspirations? Journal of Business Venturing 28(4), 564-580.

Godfrey, P. C. (2011). Toward a theory of the informal economy. The Academy of Management Annals, 5(1), 231-277.

Levie, J., \& Autio, E. (2011). Regulatory burden, rule of law, and entry of strategic entrepreneurs: An international panel study. Journal of Management Studies, 48(6), $1392-1419$.

Minniti, M., Arenius, P., \& Langowitz, N. (2005). Global entrepreneurship monitor 2004 report on women and entrepreneurship. London and Babson Park, MA: London Business School and Babson College.

Peng, M. W. (2002). Towards an institution-based view of business strategy. Asia Pacific Journal of Management, 19(2/3), 251.

Reynolds, P. D. (2007). New firm creation in the United States: A PSED I overview. Foundations and Trends in Entrepreneurship, 3, 1-149.

Reynolds, P. D, Bosma, N., Autio, E., Hunt, S., De Bono, N., Servais, I., et al. (2005). Global entrepreneurship monitor: Data collection design and implementation: 1998-2003. Small Business Economics, 24, 205-231.

Reynolds, P.D., Hay, M., \& Camp, S. M. (1999). Global entrepreneurship monitor executive report 1999. London and Babson Park MA: London Business School and Babson College.

Reynolds, P.D., Camp, S. M., Bygrave, W.D., Auito, E. \& Hay, M. (2001). Global entrepreneurship monitor executive report 2001. London and Babson Park MA: London Business School and Babson College. 
Reynolds, P.D. \& White, S.B. (1997). The entrepreneurial process: Economic growth, women, and minorities. Westport, CT: Greenwood Publishing Group, Inc.

van Stel, A., Storey, D. J., \& Thurik, R. (2007). The effect of business regulations on nascent and young business entrepreneurship. Small Business Economics, 28(2/3), 171.

Weitzel, U., Urbig, D., Desai, S., Sanders, M. \& Acs, Z. (2010). The good, the bad, and the talented: Entrepreneurial talent and selfish behavior. Journal of Economic Behavior \& Organization, 76(1), 64-81. 